\title{
Motive-based enforcement
}

\author{
Wim Voermans ${ }^{1}$ \\ 'There are not enough jails, not enough policemen, not even enough courts \\ to enforce a law not supported by the people'
}

Hubert H. Humphrey (vice-president USA 1964-1968)

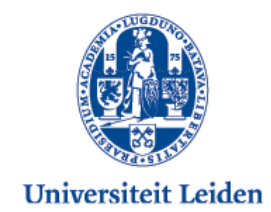

Abstract

What can public authorities do in order to promote regulatory compliance? This paper argues that understanding the compliance motives is key to any enforcement strategy. Simply stepping up the enforcement effort or stiffening penalties is - most of the time - quite ineffective. Especially attempts at engineering criminal law rules to achieve a heightened deterrence effects will generally be ineffective, social science research suggests. And - much in the same vein - raising administrative enforcement efforts does not automatically raise compliance rates proportionally. There is not a one-on-one relation between enforcement effort and compliance outcome, although this idea seems to be underpinning a lot of present-day enforcement strategies. Enforcement efforts are but one of the many norm-support cues to comply. Recent research rather suggests that a sort of bandwagon-effect exists as regards regulatory compliance. Compliant behaviour, or enforcement activities that reminds us of (or merely point out) the existence of a norm, prompt

1 Wim Voermans is Professor of Constitutional and Administrative law at Leiden University, Director of the Institute of Public Law at Leiden Law School and President of the International Association for Legislation. This contribution is loosely based on a speech I gave some years ago for the Dutch Association for Legislation, which I presided at the time. The speech was published in the annual conference proceedings of the Association. W. Voermans (2007), De aspirinewerking van sanctioneren (The Aspirin Effect of Sanctioning), in: L. Loeber (ed.), Bruikbare wetgeving (Useful Legislation), preadviezen van Ph. Eijlander en P. Popelier aan de Vereniging voor wetgeving en wetgevingsbeleid. Wolff Legal Publishers: Nijmegen, p. 57-64. 
(more) compliant behaviour. Designers of enforcement strategies need to keep this in mind.

\section{Compliance as a prerequisite for effective regulation}

Compliance is essential for the operation of regulation. ${ }^{2}$ Rules and regulations that are not systematically observed are - in the end - pointless and futile. The overarching aim of all regulation is to have an effect on (social, economic, or institutional) behaviour; to impact behaviour by means of legal effect. 'To be authoritative', Tom Tyler argues, 'legal rules and decisions must affect the actions of those toward whom they are directed. ${ }^{3}$ If they do not, the authority of the legal rules themselves may be compromised. Lon Fuller observes that:

'On the one hand, the lawgiver must be able to anticipate that the citizenry as a whole will accept as law and generally observe the body of rules he has promulgated. On the other hand, the legal subject must be able to anticipate that government will itself abide by its own declared rules when it comes to judge his actions, as in deciding, for example, whether he has committed a crime or claims property under a valid deed. A gross failure in the realization of either of these anticipations - of government toward citizen and of citizen toward government - can have the result that the most carefully drafted code will fail to become a functioning system of law. ${ }^{4}$

Compliance, in fact, is the double-edged sword of all regulation: it is crucial for the effect of law and it reinforces the authority of law, while noncompliance cripples the effectiveness of law and undermines the authority of it.

\footnotetext{
${ }^{2}$ There is a wide variety of definitions of the concept of regulation. For this contribution I will use a very wide ranging definition of the concept of regulation and understand it as every public or state-based (as opposed to market-based) intervention in the form of a legal act of a general nature (i.e. not merely directed at one individual or a single event).

3 Tom R. Tyler (2006), Why do People Obey the Law. Princeton University Press, p. 19.

${ }^{4}$ Lon L. Fuller (1969), Human Interaction and the Law, American Journal of Jurisprudence (14) 1, p. 24.
} 
As a result legal authorities all over the world are interested in securing compliance with the law, Tom Tyler notes

'legal authorities want to establish and maintain conditions lead the public generally their decisions and policies. ${ }^{5}$

This is not easy, because legal authorities cannot, as we all know from experience, take public compliance for granted. ${ }^{6}$

How do public authorities set these conditions to inspire and optimize compliance with regulations? What kind of problems do they face, what kind of standards are they subject to? What strategies do they employ? And can anything be said about the success of these strategies? Do best practices exist? These are the question that are central to this contribution. Before we deal with the standards, strategies, instruments and best practices of compliance - in my experience in most cases the ill-advised starting point of policy debates on compliance - we need to understand why people (including institutions, market operators, etc.) comply with rules. Every compliance policy, strategy or instrument that fails to take the motives and attitudes of addressees into account, risks being ineffective in the end. ${ }^{7}$

\section{Understanding compliance: rational and constructivist compliance theories}

Why do people actually obey the law? A host of theories have attempted to solve this riddle. ${ }^{8}$ According to one line of thinking - one that is quite common in present-day administrative and regulatory practice - the answer to these questions is quite straightforward. It departs from the notion that the

5 Tyler (2006), p. 19.

${ }^{6}$ Tyler (2006), ibid.

7 See also R.A.J. van Gestel (2013), De wetgever als keuzearchitect (Regulating as the art of choice architecture), RegelMaat (Journal for Legislative Studies (28), 1, p. 22-38.

${ }^{8}$ Most of these theories have originated in international law, an area of law where compliance is especially hard to enforce. Although originally devised to understand the behaviour of states, or state-based institutions these theories can also be used to gain a better understanding of (non)compliant behaviour of actual people. See for an overview Ronald B. Mitchell (1996), 'Compliance Theory: An Overview' in: James Cameron, Jacob Werksman, and Peter Roderick, Improving Compliance with International Environmental Law. Earthscan 1996, p. 3-28. 
principle actor in compliance is the administration itself. Compliance with enacted regulation is inspired by a combination of due process when enacting and proper communication of the rules (publication and promulgation) and making administrative efforts to ensure the acceptance of rules (by giving additional information, dialogue, monitoring, etc.) or other methods that could contribute to voluntary or 'spontaneous' compliance with these rules. ${ }^{9}$ If compliance does not ensue, according to this line of thinking, the administration can be held to account. It needs to gather information with regard to compliance and non-compliance with the regulation (monitor \& inspect) and react to nonconformity (enforce, sanction). This line of thinking branches out into two different perspectives on the issue in modern compliance theory. The first is the rational perspective (believing that regulatory addressees are rational actors that weigh cost and benefits and believing therefore that only a coercive strategy of monitoring and sanctioning will induce compliance, hence also known as the enforcement school). ${ }^{10}$ The second perspective is the management perspective which also perceives regulatory addressees as rational beings, but recognizing that noncompliance is not always per se the result of deliberate defiance of the regulation. It also occurs as a result of capacity limitations on the part of the addressee, as a result of ambiguity of rules, or involuntary and inadvertently for a number of other reasons. ${ }^{11}$ Non-compliant behaviour therefore does not always need to be 'cured', remedied or followed by administrative enforcement or sanctions, but may be secured by remedial forms of administrative action (information, administrative assistance, legislative simplification, etc. $)^{12}$ According to both perspectives though, compliance is largely dependent on administrative action. In the constructivist perspective - on the other hand - compliance is dependent on the way regulatory norms tie in with or align with the beliefs of the addressee. According to constructivist

\footnotetext{
${ }^{9}$ This line of thinking can be found in the compliance toolbox the Dutch government uses, called the Table of 11 . The number refers to the eleven dimensions of compliance the instruments use as steps that help users to assess the chances of success of their compliance strategy of instrument.

${ }^{10}$ Jeffrey T. Checkel (2001), Why Comply? Social Learning and European Identity Change, International Organization (55) 3, p. 555-557. See also Esther Versluis (2005), Compliance Problems in the EU; What potential role for agencies in securing compliance, Paper prepared for the $3^{\text {rd }}$ ECPR General Conference, Budapest 2005. To be retrieved at: http://regulation.upf.edu/ecpr-05-papers/eversluis.pdf (last visited on 4 February 2013).

${ }^{11}$ Versluis (2005), p. 8-9.

${ }^{12}$ Jonas Tallberg (2002). Paths to Compliance: Enforcement, Management, and the European Union, International Organization, 56, p. 609-643, notably p. 613.
} 
theory the main driver for the change of behaviour (or preferences) is not external (e.g. administrative action), but rather more the socialization or internalization of rules by the addressees. ${ }^{13}$ Internalization, as it were. Socialization and internationalization of rules, in turn, are predominantly brought about by persuasion and/or persuasive appeals to inner morality. If regulators succeed in convincing addressees that rules are right, good, necessary, legitimate or whatever successful appeal can be made to the inner motivation or belief system of the addressee and spontaneous compliance might ensue. And if we may believe the evidence our own eyes bring us, spontaneous compliance is the general effect in established liberal democracies - at least in absolute terms - whatever persistent non-compliance problems these political systems face. Versluis makes clear, however, that constructivism, on the other hand, does not provide clear-cut short-term solutions to solve compliance problems. ${ }^{14}$ Internalization and socialization, and thus compliance, will only take place in the long run; no quick fixes here.

\section{Implementation \& enforcement: legal standards}

Although we do not want to dwell on legal theory too long, it would seem we must admit that in essence law is a 'belief' system. We abide by the law because we believe we have to and/or other members of our societies, or state actors remind us we ought to. ${ }^{15}$ Regulation uses the law as its vehicle and by that appeals to the beliefs of its addressees. ${ }^{16}$ In liberal democracies, based on the rule of law, the law system itself calls upon the public authorities to act and to implement, i.e. guarantee the effect of law, if necessary by

\footnotetext{
${ }^{13}$ Or as Raustalia and Slaughter put it: 'From a constructivist perspective, compliance is less a matter of rational calculation or imposed constraints than of internalized identities and norms of appropriate behaviour.' Kal Raustiala \& Anne-Marie Slaughter (2002), 'International Law, International Relations and Compliance', in W. Carlsnaes, T. Risse \& B.A. Simmons, Handbook of International Relations. Sage; London, p. 540.

14 Versluis (2005), p. 11.

15 These beliefs in turn are very important, because they are legitimate rules and government action is required to enforce them. If rules and government action is perceived as legitimate (in terms of effectiveness and fairness) the more it will possess the potential to elicit compliance without excessive monitoring or punitive action. See Margret Lev and Audrey Sacks (2009), Legitimating beliefs: Sources and indicators, Regulation \& Governance (3), p. 311.

${ }_{16}$ David Beetham (1991), The Legitimation of Power. Palgrave MacMillan, p. 69-70 ff. and p. 91.
} 
way of enforcement. The duty to implement ${ }^{17}$ and enforce laws is generally perceived as something required by the rule of law. Compliance fosters the basic trust people can have in the law, it reinforces the authority of the law and thereby its overall legitimacy. Although public authorities in the rule of law-based jurisdictions are under the obligation to implement law, and enforce it if necessary, they do not have total discretion in doing so. Implementation and enforcement activities generally need to have a basis in law as well, and the law itself sets conditions for implementation. A legal principle that is quite well known and common to most rule-of-law-based jurisdictions is the 'nulla poena sine lege priori'-principle entailing that no one shall be held guilty of any criminal offence on account of any act or omission which did not constitute a criminal offence under national or international law at the time it was committed; nor shall a heavier penalty be imposed than the one that was applicable at the time the criminal offence was committed. This principle is enshrined in article 7 of the European Convention on Human Rights (ECHR), but also in article 15 of International Covenant on Civil and Political Rights, and other documents. Closely related to this principle is the 'lex certa'-principle which requires that - in particular criminal - offences must be clearly specified, that they must be foreseeable and that it must be possible to clearly determine, on the basis of the relevant legal provisions, the acts or omissions prohibited. Another principle derived from article 7 ECHR is the principle of non-retroactivity holding that an act cannot be designated as criminal by the courts if it has not been punishable previously, and the definition of existing criminal offences cannot be extended to acts which have not previously constituted an offence. It is not our aim here to give an exhaustive overview of legal requirements, principles and standards that are relevant for implementation and enforcement activities, but we will deal with two more that are especially relevant in ECHR and EU Member States. The first one is the proportionality-principle, requiring that enforcement action (including sanctions) may not be disproportionate to the goals served. Another important principle - especially in the EU context - requires that EU Member States act loyally and effectively when it comes to observing, implementing/enforcing EU law. EU Member States are under a legal obligation to implement and enforce EU law ${ }^{18}$ and ECJ case law on enforceability of EU law requires that penalties for violation

${ }^{17}$ I use the term 'implementation' in a broad sense comprising of all efforts and activities involved in achieving the goals of legislation. These efforts cover a wide range of actions, ranging from issuing licenses, policing, inspecting, to enforcing (sanctioning, etc.). In my view enforcement, therefore, is a part of implementation.

18 Art. 4 (3) Treaty of the European Union. 
(of EU Law) should be effective, proportionate, non-discriminatory and dissuasive. ${ }^{19}$ Effectiveness requires that the set sanction furthers the goals set by the legislature, dissuasive - understood here in terms of deterrence means that sanctions should be of such a type and magnitude that the expected costs are higher than expected benefits to the perpetrator, proportionality requires that the sanctions are no severer than they strictly should be. Finally sanctions may not be discriminatory, meaning that conditions attached to the national rules may not be less favourable than those attached to similar national actions. And second, the national rules may not be framed in a manner that would render the exercise of Community rights virtually impossible.

\section{Enforcement strategies}

There is a substantial body of literature nowadays on enforcement and compliance strategies. ${ }^{20}$ Most of the literature departs from the notion that regulatory agencies have considerable administrative discretion when carrying out their enforcement tasks. ${ }^{21}$ Even if we take into account that enforcement discretion is curtailed by legal standards (as we have seen in the former paragraph), this is a fair assessment of the position of regulatory agencies in most European countries. This leaves regulatory agencies - in broad terms a choice of enforcement styles or strategies. There are basically two enforcement strategies (or styles). The first is the deterrence strategy which in the words of Gunningham - 'emphasizes a confrontational style of enforcement and the sanctioning of rule-breaking behaviour. It assumes that those regulated are rational actors capable of responding to incentives, and that if offenders are detected with sufficient frequency and punished with sufficient severity, then they and other potential violators, will be deterred from violations in the future.' 22 The compliance strategy on the other hand, seeks to prevent harm rather than punish it and focuses on cooperation between regulator, enforcement authority and addressee rather than confronta-

\footnotetext{
${ }^{19}$ ECJ C-68/88 Commission v. Greece [1989] ECR 2979 (Greek Corn-case). 20 See for an overview e.g. Neil Gunningham (2010), Enforcement and Compliance Strategies, in: Robert Baldwin, Martin Cave and Martin Lodge (eds.), The Oxford Handbook of Regulation. Oxford University Press, chapter 7 (p. 120-145) and Bronwen Morgan \&Karen Yeung (2007), An Introduction in Law and Regulation. Cambridge University Press, Chapter 4, p. 151-220.

${ }^{21}$ Gunningham (2010), p. 121.

22 Gunningham (2010) ibid.
} 
tion, and conciliation rather than coercion. ${ }^{23}$ Compliance strategies adhere to communication, bargaining and negotiating, using enforcement more or less as a mere threat, a big stick in the background. Recent research has shown that both strategies - in their basic form - are not very effective. Basically - though it does have a significant impact - the deterrence strategy is vulnerable with regard to the costs, incompetent or non-rational actors and it sometimes has counterproductive consequences (e.g. in the form of a 'culture of regulatory resistance'). ${ }^{24}$ Compliance strategies on the other hand although they encourage and facilitate those willing to comply with the law - are vulnerable to the strategic behaviour of those not wanting to comply voluntarily. ${ }^{25}$ What then is the best way to go? On the basis of game theory analysis, Scholz ${ }^{26}$ has demonstrated that a tit-for-tat (TFT) enforcement strategy most probably yield the best result. A TFT strategy entails that the regulator refrains from a deterrent response so long the addressee is cooperating, but when the addressee begins to exploit the cooperative posture of the regulator and cheats on compliance, then the regulator shifts from a cooperative to a deterrent response. One way to operationalize this notion of a third way that lies between deterrence and cooperation is that of responsive regulation. ${ }^{27}$ Responsive regulation is an approach that encourages authorities to read motivational postures, understand the sensibilities that shape them, and tailor a regulatory intervention accordingly. A carrot and stick approach, rewarding voluntary compliance and cooperation and punishing if necessary - conscious and determined offenders. Ayres and Braithwaite have tried to come up with a mechanism to solve this problem, their socalled Enforcement Pyramid. ${ }^{28}$ The pyramid departs from a cooperative stance with regard to non-compliance but gradually gears up to a more deterrent response if the desired compliance result is not forthcoming.

\footnotetext{
${ }^{23}$ Gunningham (2010) ibid.

${ }^{24}$ Gunningham (2010), p. 139.

${ }^{25}$ Gunningham (2010) ibid.

${ }^{26} \mathrm{~J}$. Scholz (1984), Deterrence, cooperation and the ecology of regulatory enforcement, Law and Society Review (18), p. 179-224.

${ }^{27}$ I. Ayres, \& J. Braithwaite, (1992). Responsive regulation. Transcending the deregulation debate. New York: Oxford University Press.

${ }^{28}$ Ayres and Braithwaite (1992), p. 35.
} 


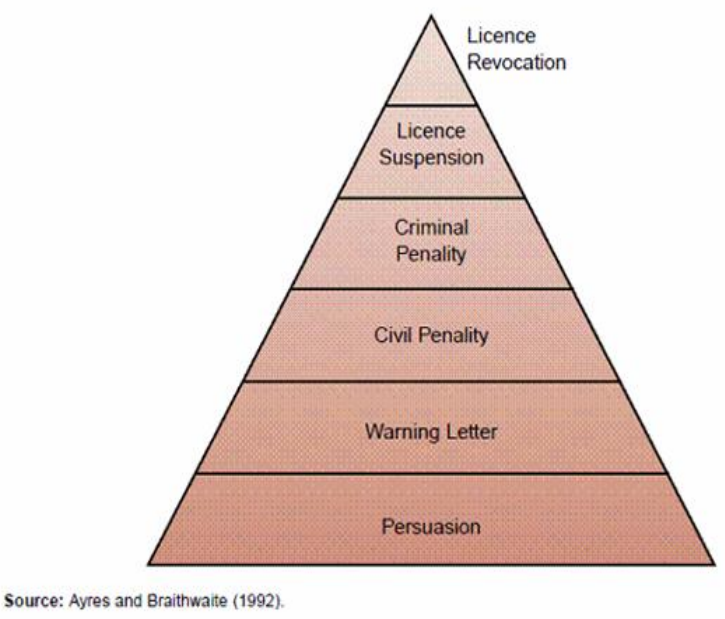

The pyramid, at least the notion underlying it, is widely adopted in enforcement practice.

Gunningham and Grabosky have noted that enforcement strategies that rely solely on action by regulatory authorities do come with drawbacks when it comes down to costs and internalization - even when cooperative and deterrent elements are mixed. They have advocated the concept of 'Smart regulation'. Smart regulation - not to be confused with the EU better regulation strategy $^{29}$ - refers to a form of regulatory pluralism that embraces flexible, imaginative and innovative forms of social control which seeks to harness not just government but also business and third parties. It uses selfregulation and co-regulation, forms of private enforcement and a host of other policy instruments to improve the overall effectiveness of more conventional forms of direct government action. ${ }^{30}$ A last enforcement strategy to be discussed here is the 'meta-regulation' or 'meta-risk management'. This latter strategy involves the government not regulating directly to ward off risks (to health, safety, public order, markets, etc.) but rather more overseeing (risk-managing) the risk management of individual enterprises. In such a system government inspectors - when checking compliance - encourage industry to put an internal risk control and management system in place which is in turn scrutinized by regulators. It is the control and man-

\footnotetext{
${ }^{29}$ See the Smart Regulation Communication $\operatorname{COM}(2010) 543$ final http://eurlex.europa.eu/LexUriServ/LexUriServ.do?uri=COM:2010:0543:FIN:EN:HTML last consulted on 7 February 2013.

${ }^{30}$ N. Gunningham, P. Grabosky, \& D. Sinclair (1998), Smart Regulation, Designing Environmental Policy. Oxford: Clarendon.
} 
agement systems that are inspected rather than the actual behaviour of the enterprises. $^{31}$

Although the strategies mentioned here are very relevant to our topic, they do not answer the question as to how these strategies can be put to use when actually setting up and drafting legislation. The literature at hand tends to focus on regulatory agencies and their strategies. What can be learnt from this that could be helpful to set up a course of action for the practice of legislative drafting?

\section{Enforcement strategies in legislative and policy practice}

When it comes to regulation, the philosopher's stone is of course: are there any failsafe compliance controls around in regulation and if so, where are they to be found? And, more so, how do you turn them on or off? Or up and down? These are highly relevant questions in times where there are frequent calls for higher and more stringent penalties and more intensive enforcement as a means to combat regulatory non-compliance.

How can one exert influence on regulatory compliance? According to a well-known recipe from the legislator's cookery book, regulatory compliance is primarily promoted through proper communication of the rules (publication, provision of information) and making an effort to ensure the acceptance of rules and to apply other methods that could contribute to voluntary or 'spontaneous' compliance with these rules. ${ }^{32}$ This is what we would obviously prefer and it chimes well with the theory and evidence that legitimation is the key to compliance (paragraph 3) and that mixed enforcement strategies, that start with investing in a persuasive compliance strategy, but can escalate the response as the situation may require, probably work best.

Indeed in many cases regulators cannot simply rely on voluntary compliance with rules, but need to do more. Especially when regulating cases in which non-compliance may yield financial benefits, compliance monitoring (through forms of supervision or investigation) - according to wisdom

\footnotetext{
31 Gunningham (2010), p. 135-139.

32 See, again, for example, the Dutch Table of 11.
} 
gained through legislative practice - the threat and actual application of sanctions is necessary to ensure effective compliance. ${ }^{33}$

The guiding notion in Dutch regulatory practice - which we will discuss here as an example - is that, where a government makes extra efforts to ensure regulatory compliance - by exercising effective supervision and/or using private law, criminal law or administrative means of coercion (sanctions) - this will increase regulatory compliance, more or less in a linear way. ${ }^{34}$ In the Netherlands, as in many other countries, the enforcement debate has consequently been captured by discussion on the way government can and must step up its enforcement efforts and - in parallel - on the use of techniques and instruments by government agencies. As a result, toolboxes are rampant in Dutch public administration. For the sake of the discussion we will label this line of reasoning as administrative logic.

As we have seen, however, there is at best an uncertain relationship between enforcement efforts by government agencies on the one hand and their impact on compliance on the other. If we want to predict the impact public enforcement efforts and instruments have on compliance it does not suffice to simply focus on toolboxes, strategies and techniques. As we have demonstrated in the former paragraphs, any policy or strategy trying to improve regulatory compliance must not start with a discussion on the toolkit, but with an understanding of why citizens and companies comply with rules and what role is played by enforcement efforts in this context. In other words, we should - when devising compliance policies - not merely rely on administrative logic but also think in terms of the logic of motives. ${ }^{35}$

\footnotetext{
33 On this subject, see also P. Eijlander and W. Voermans (2000), Wetgevingsleer (Legislative drafting). Boom Legal Publishers; The Hague, p. 156 et seq.

${ }^{34}$ This approach can also be found in the case law of the European Court of Justice in which the Court sets out the enforcement principles in explicit terms. Reactions to non-compliance with EU rules must be effective, proportional, have a deterrent effect and satisfy the assimilation principle as it is called. See Eijlander \& Voermans (2000), p. 288.

${ }_{35}$ Picking up on this latter line of thinking Van Gestel argues that regulatory policies which include compliance policies - could benefit from behavioural approaches to law and economics; an increasingly important and relevant field of academic research. He bases his views on a.o. C. Jolls, C. Sunstein \& R. Thaler (1998), A Behavioural Approach to Law and Economics, Stanford Law Review, (50) 1471, p. 1476; R.H. Thaler \& C.R. Sunstein (2008), Nudge: Improving Decisions about Health, Wealth and Happiness. Yale University Press. See Van Gestel (2013), p. 25-26.
} 


\section{Enforcement debate in the Netherlands: the Michiels Commission}

Paying due attention to compliance motives, however, seems to be tough going in politics and policy making. Enforcement debates often utterly fail to deal with the effect caused by an enforcement incentive on the addressee but - in quite a one-sided fashion - they rather more address the question of what kind of enforcement incentive should be offered by what law enforcement agency. This is - as we have seen - based on the axiom that enforcement has a beneficial effect on compliance. Always and universally. The proof for this assumption is often found by pointing out the opposite: nonenforcement in any case results in non-compliance or a greater chance of non-compliance. Keen observers will, of course, immediately recognize this reversal as a fallacy.

Allow us to give an illustrative Dutch example. In the 1990s, the Dutch government was much concerned with so-called enforcement deficits, i.e. a situation of regulatory non-compliance in situations where there was a demonstrable existing enforcement capacity. Obviously in these situations administrative capacity was - at the face of things - not well aligned with the relevant needs. In order to tackle this problem the Government set up the Michiels Commission. ${ }^{36}$ In its final report from 1998, ${ }^{37}$ this Commission, too, assumes the existence of the presumably beneficial but essentially unknown and unproved relationship between enforcement efforts and compliance. The commission adopts a risk-based approach, however, by stating that where there is no enforcement, the risk of non-compliance is substantial. Therefore the Commission advises , somewhat unsurprisingly, that in the case of non-compliance, administrative enforcement efforts should be intensified. Always. Compliance policies in the Netherlands followed suit. An action programme set up by the Dutch Government in response to the report - entitled Handhaven op niveau ('Quality Enforcement') - underlining the importance of strenuous administrative efforts. Better cooperation and ongoing professionalization of enforcement efforts were supposed to result in potential enforcement deficits being made up or reduced, the elimina-

\footnotetext{
36 The Dutch Commission for Administrative and Private Law Enforcement ('Michiels Commission').

37 The Commission for Administrative and Private Law Enforcement, Handhaven op Niveau ('Quality Enforcement'), Deventer, 1998, p. 47.
} 
tion of the risks of non-compliance, and a potentially beneficial effect on compliance. ${ }^{38}$

Dealing with risks in this way resembles homeopathy or the effects of aspirin: we assume that enforcement works; indeed, we know that it works, but we do not know how it works or the extent to which it works. And any physician will tell you that there is the risk of a wrong dose in cases like that.

This administrative approach to the relationship between enforcement and compliance can also be found in the evaluation report about the 'yield' of the 'Quality Enforcement' programme. At the closing conference of the programme, which was held in The Hague on 24 November 2006, the many successes of the programme were recalled. It was pointed out that since 1999, administrative bodies had devoted greater attention to the enforcement of statutory and other rules. The programme project monitor showed that by then, 83 percent of Dutch municipalities had 'a great deal of attention' for enforcement. In specific policy fields - including compulsory education and prostitution policy, for example, being policy fields that involved hardly any inspections five years ago - there was an increase in inspection efforts from 20 to 70 percent. Special enforcement programmes had been set up by 63 percent of the municipalities. Five years before, it was claimed, not a single municipality had been engaged in such programmes. In addition, half of the municipalities had by 2006 identified the risks of disasters as a result of non-compliance with statutory rules.

The Quality Enforcement programme also promoted the professionalization of enforcement and mutual cooperation between municipalities, provinces and water boards and cooperation with the police and inspection bodies. The Project Monitor from 2005 showed that these bodies had actually started to cooperate more closely, especially in the fields of the environment, public space enforcement, living conditions, fire safety and building control. According to 95 percent of the Dutch municipalities in 2006, the Quality Enforce-

38 See also the Government position paper on Handhaven op level, Parliamentary Papers II 1999/2000, 26800 VI Adoption of the budget of the income and expenses of the Ministry of Justice (VI) for the year 2000, No. 67. 
ment action programme had improved enforcement to a significant extent. $^{39}$

\begin{abstract}
All of the results were expressed in terms of administrative efforts while little could be said apparently about the extent to which and the manner in which the enforcement incentive worked on actual compliance. The principle effects of programme-based enforcement were primarily to be found in the area of awareness and risk control. In his letter to the Dutch House of Representatives, the Minister of the Interior at the time, Mr Remkes, was therefore not altogether convinced of the success of the programme, aside the evidence produced by the evaluation report . He - quite realistically - stated that:
\end{abstract}

'Even though attention for specific topics (such as fire safety, outlying areas, compulsory education) has resulted in greater awareness, the practical contribution of 'Quality Enforcement' is limited in many cases. People's opinions on the matter differ but many are critical. Its potential has not yet been realised in most cases. ${ }^{40}$

\title{
7. Instruments of compliance: enforcement and sanctions
}

\subsection{The deterrent effect of punishment as a motive for regulatory compli- ance}

But how then to use the enforcement capacity to good effect? As we have argued this requires some understanding of the effects of enforcement efforts on regulatory compliance. As a first step we need to know something about the why of regulatory compliance. As this is a wide-ranging issue, that cannot be dealt with to the full extent in this contribution, we will restrict ourselves to the element of the effectiveness of sanctioning, and, in particular, to the threat of punishment. Does the threat of punishment deter non-compliers, does it inspire them to comply with rules? And, for example, will higher penalties - as an expression of increased enforcement activity -

\footnotetext{
${ }^{39}$ See www.rijksoverheid.nl/...en.../samenwerken-daar-zit-muziek-in.pdf

${ }^{40}$ Letter from the Minister of Justice to the Dutch House of Representatives, dated 6 November 2006, offer of evaluation of action programme 'Quality Enforcement', see http://www.justitie.nl/images/ 20Handhaven\%20op\%20Niveau_6534 tcm34-25550.pdf. evaluatie $\%$
} 
be more effective than lower ones? For centuries, legal scholars have had disputes and debates on the question of whether penalties are an effective means to ensure regulatory compliance. In recent years criminologists, legal economists and forensic psychologists, in particular, have dealt with these issues. The participants in the debate are somewhat like doctors gathered round a sickbed: there are many differences of opinion about the diagnosis and treatment, and there seems little prospect of any recovery.

The debate is fierce at times. Certainly where recent research plays down the effects of punishment or more severe penalties, this occasionally triggers fierce reactions and touches a raw nerve. A Dutch journalist, for example, wrote in an article entitled 'More Severe Punishments Are Effective' that our intuition, 'our common sense', ${ }^{41}$ tells us that more severe punishments are effective. Perhaps not because this is really the case, but because we think this should be the case. As a result, punishments and the threat of punishment are not only an instrumental but also a moral issue, not just for noncompliers but also for compliers.

\subsection{Explanations for compliance and non-compliance}

It is not easy to explain why rules are complied with and what role punishment plays in this respect. It is already a problem to define humans in this context. If we assume that humans are rational, calculating beings (homo economicus), ${ }^{42}$ punishments and threats of punishment that make the chance of a loss (sanction or another disadvantage) greater than the benefit gained as a result of any non-compliance are effective. According to this line of reasoning, stiffer penalties and an increased chance of being caught will deter potential non-compliers to a greater extent than lower penalties. The legislator could latch on to this by developing 'compliance mathematics'.

${ }^{41}$ From Henry Sturman (2003), 'Zwaarder straffen werkt', Elsevier 17 January 2003, available on http://www.libertarian.nl/NL/archives/straffen.pdf.

42 'Econs' as Thaler and Sunstein (2008) call them. But recent research shows that human (market) behaviour is not only guided by reason and logic but also by 'predictable' irrational choices. See Jolls, Sunstein \& Thaler (1998) as cited by Van Gestel (2013), p. 25-26. 
In 1994, the Dutch economist Van Velthoven conducted an amusing study of the economy of crime and punishment. ${ }^{43}$ Based on the reference year 1990, he made a calculation of the expected punishment and benefits per crime for the Dutch situation. The clear-up rate for the crimes registered by the police was 22.3 percent in the Netherlands at the time. ${ }^{44}$ The Dutch Central Bureau for Statistics (CBS) estimate however that the actual number of crimes committed against private individuals (6.3 million) and institutions and companies (5.4 million) actually is ten times higher than the number of the registered crimes. On that basis Van Velthoven calculated that the actual chance of being caught for a crime in the Netherlands was only about 2.2 percent. If we take into consideration that only six percent of the criminals caught were given a prison sentence, this results in an actual chance of imprisonment of 1 out of 758 per crime committed. In addition to imprisonment, fines were imposed, but these were very low, too. Van Velthoven's final conclusion is that the expected threat of punishment per crime equals a fine of only NLG 3.60 (approx. €1.50 present-day value) plus four hours' imprisonment. On the other hand, the expected benefits per crime were more than NLG 400 (approx. €180). If the financial implications are assessed in more general terms, crime benefited everyone who earned less than NLG 100 (approx. $€ 45$ ) per hour in a normal job in 1990. That is to say, more than $95 \%$ of the population. ${ }^{45}$

The present-day figures for the Netherlands will probably be a little more favourable, though perhaps not significantly different. According to the calculations of Van Velthoven's study, a calculating person - econs - will always consider non-compliance to be the more advantageous option. And yet, most citizens are law-abiding people. Why?

Perhaps, this is because we are all different. It is a fact of life that there are good guys and bad guys. Threat of punishment would then be especially effective for calculating and prospective criminals. This may also be connected with the fact that citizens and companies do not calculate their

\footnotetext{
${ }^{43}$ He reiterates the method of calculation and outcomes in his newest book. B. C.J. van Velthoven (2012), Economie van misdaad en straf (The Economy of Crime and Punishment). Boom Lemma Publishers, p. 39-44.

44 The clear-up rate did improve somewhat over time, at present (2013) it is about $25 \%$.

45 Source that reported on the research Het Parool (a Dutch newspaper) 28 June 2002.
} 
chances in this simple manner, but include more factors in their calculation than the mere threat of punishment and the chance of being caught. ${ }^{46}$ These factors include reputation, the information at hand (most people do not know the sanctions or the exact figures of the chance of being caught, etc.), culture, morality, ${ }^{47}$ the subjective chance of being caught. As Van Velthoven in his latest book argues, it is not the objective chance of being caught that is most important to prospective delinquents but the subjective chance of it, i.e. the chance of being caught as the prospective delinquent perceives it. ${ }^{48}$

In recent years, Henk Elffers, a forensic psychologist, has tried to address these questions as well. In 1997, Elffers, together with Hessing, examined the role of the threat of punishment related to compliance with tax legislation (income tax). ${ }^{49}$ They drew the following remarkable conclusions:

- Statutory sanctions are ineffective for - what they call - the conformist compliers, i.e. those who comply with rules only because they fear punishment. There is only an effect if - and that does not seem feasible, and perhaps not desirable either - the punishment threatened is certain, quick and severe.

- Statutory sanctions have an indirect effect on the identifiers, those who comply with rules because they want to belong to a social group for which compliance is the norm; imposing sanctions on the others, those who break the rules, is necessary and useful for the identifiers, because this serves to maintain the social norm for them, the norm that keeps them on the straight and narrow.

- Statutory sanctions are superfluous for the internalisers, those who comply with rules because they have made these rules part of their own world view.

That the threat of punishment has an indirect effect on identifiers is an important research finding, which is also confirmed in other recent studies, like the one conducted by the Swede Lennart Wittberg in his contribution to

\footnotetext{
${ }^{46}$ On this subject, see H. Elffers (2005), De rationele regelovertreder (The Rational Delinquent), inaugural address for Antwerp University, 26 October 2004, Boom Legal Publishers.

${ }^{47}$ Van Velthoven (2012), p. 49-52.

${ }^{48}$ Van Velthoven (2012), p. 41.

${ }^{49}$ See Henk Elffers and Dick J. Hessing (1997), Het nut van sanctions (The Usefulness of Sanctions), Ars Aequi (Dutch Student Law Magazine), 46, p. 490-496.
} 
the recent conference publication entitled Managing and maintaining compliance. ${ }^{50}$ He concludes from his experiences of Swedish tax legislation that punishment voices a significant signal. The importance of that signal does not primarily lie in the deterrence of the prospective non-complier but in the fact that the punishment of non-compliers confirms the existence and operation of rules to those other than the non-complier. Punishment impresses the relevant rule on the minds of people and programmes our willingness to comply with rules. In other words: a sort of bandwagon-effect exists as regards regulatory compliance.

\subsection{Differential Attributions}

This pattern is also confirmed by Catherine Anderson and John Darley, who published a report in the Journal for Applied Social Psychology in 2002 about four experiments in which they asked respondents about their motives for complying with rules. The interesting aspect is that, even if they are notorious non-compliers, many of these respondents indicate that they themselves are restrained from non-compliance as a result of internal factors (morality, internalisation) and not because of the supposed consequences of noncompliance. However, and this brings us to the crux of the matter: they do assume at the same time that others - certainly other non-compliers - are probably restrained from non-compliance only because of the risk of punishment or the consequences (external factors). ${ }^{51}$ In other words, a 'distrust model', which is well in line with the 'arrangement nature' that underlies the law and the confidence that parties under the law derive from that. Accordingly, punishment and the threat of punishment are primarily intended to ensure that others will adhere to the arrangement made.

The survey conducted by Anderson and Darley is particularly amusing if the results are applied to legislators. Let us assume, for the sake of convenience, that these are just ordinary people, too. If this is so, they will probably devise punishment threats which they believe they do not need themselves but which will deter others. Yet, these threats do not deter others very much because the experiment shows that deterrence through the threat of punishment is not the principal motive for compliance.

\footnotetext{
${ }^{50}$ Lennart Wittberg (2006), Can Communication Activities Improve Compliance?, in: H. Elffers, P. Verboon and W. Huisman (ed.) Managing and Maintaining Compliance, Boom Legal Publishers; The Hague 2006, p. 25-43.

${ }^{51}$ Catherine A. Sanderson and John M. Darley (2002), I Am Moral, but You Are Deterred: Differential Attributions About Why People Obey the Law, Journal of Applied Psychology, 2002, 32, 2, p. 375-405.
} 


\section{Conclusion}

What can we learn from all this ? Quite a lot you would think, but not much that can be used for ready-made toolboxes that might be helpful in designing effective compliance strategies and policies. It does, however, make one reconsider whether stepping up enforcement activity or stiffening sanctions as a reaction to non-compliance, will automatically deliver a better result. There is even some disheartening evidence to the contrary. In answer to the question: 'Does criminal law deter?' Robinson's and Darley's short answer is 'no' if we consider the behavioural science data. ${ }^{52}$ Especially attempts at engineering criminal law rules to achieve heightened deterrence effects are generally ineffective social science research suggests. Potential offenders commonly do not know the legal rules, either directly or indirectly, even those rules that have been explicitly formulated to produce a behavioural effect, Robinson and Darley conclude. ${ }^{53}$ And even if they know the legal rules, potential offenders commonly cannot or will not bring such knowledge to bear to guide their conduct in their own best interests, such failure stemming from a variety of social, situational, or chemical influences. ${ }^{54}$

Does this mean that all hope is lost for legislators and enforcement agencies when they try to effect behaviour and guide it in some way or other? Certainly not. We have seen that strategies that take the motives of addressees of the rules into account, that capitalize on these motives or 'beliefs, ${ }^{, 55}$ (e.g. by way of nudges or reflecting a deeper understanding of why addressees will of will not comply with rules) may generally produce a better result.

A second conclusion that follows from the analysis is that administrative enforcement efforts do not - at least not automatically - equate compliance rates. There is not a one-on-one relation here, although this idea seems to be underpinning some present-day enforcement strategies. Enforcement efforts

\footnotetext{
${ }^{52}$ Paul H. Robinson \& John M. Darley (2004), Does Criminal Law Deter?; A Behavioural Science Investigation, Oxford Journal of Legal Studies, 42, 2, p. 173-205.

53 Robinson \& Darley (2004), p. 204.

${ }^{54}$ Robinson \& Darley (2004), ibid.

${ }^{55}$ See Margaret Levi and Audrey Sacks, Legitimating beliefs: Sources and indicators, Regulation \& Governance 2009, 3, p. 311-333. Levi and Sacks demonstrate that there is reason to believe that the more effective a government is in serving its citizens, or is perceived to be (addition WV), the more likely it is to produce a virtuous cycle of citizens compliance with its extractions, leading to better government and greater compliance. Levi \& Sacks (2009), p. 328.
} 
are but one of the many norm-support cues to comply. ${ }^{56}$ We do know there is a relationship between administrative enforcement efforts and compliance, but we do not know precisely how it works. Enforcement efforts, in other words, work like aspirin ${ }^{57}$ on compliance. This sobering truth has not kicked in everywhere still. We still have great confidence in administrative enforcement efforts as a means - in a lot of cases as the single method - to promote compliance. In sum we can conclude that in many cases the threat of punishment does not directly as a motive for regulatory compliance. Punishment and the threat of punishment have an indirect effect on regulatory compliance. Recent research also suggests that a sort of bandwagon-effect exists as regards regulatory compliance. ${ }^{58}$ Compliant behaviour, or enforcement activities that reminds us of (or merely point out) the existence of a norm, prompt (more) compliant behaviour. And finally, we believe, these insights may act as a wake-up call for the ill-advised, 'received' wisdom - so prominently at the heart of a lot of government enforcement and compliance strategies nowadays - that it is easy to guarantee compliance by adopting a system of sanction-based compliance mathematics that allow us to calculate the compliance outcome by merely adding up (and mixing) administrative action.

\section{Annex Table of 11}

In 1994, the Dutch Ministry of Justice studied the possibility of periodically monitoring the level of compliance with legislation. In the course of that project the 'Table of Eleven' originated. The 'Table of Eleven' is a model based on behavioural sciences, consisting of eleven dimensions. Together, these dimensions are decisive for the level of compliance with legislation. The eleven dimensions are formulated with a view to as high a practicability as possible in the fields of policy making and law enforcement. The dimensions provide criteria with which we can assess whether or not it is possible

\footnotetext{
${ }^{56}$ See the PhD-research of Kees Keizer, The Spreading of Disorder, PhD-thesis University of Groningen, Groningen 2010. Keizer's research shows that compliant behaviour of norm addressees is greatly influenced by the fact whether or not they observe care and respect of others (fellow citizens) for these and indeed more generally other norms. Keizer (2010), p. 90.

${ }^{57}$ A popular and effective painkiller, prescribed and used for decades although we did not understand exactly how it worked until quite recently.

${ }^{58}$ E.g. Keizer (2010).
} 
to enforce draft legislation. These criteria, however, can also be used to evaluate existing legislation.

In subsequent years, the 'Table of Eleven' was refined and improved. In addition, we gained the necessary experience in using it. These days, the 'Table of Eleven' is a household name among policy makers, jurists drafting legislation, supervisors and enforcers within the Dutch government.

See

https://docs.google.com/viewer?a=v\&q=cache:PtkFrvWH10EJ:www.sam.g ov.lv/images/modules/items/PDF/item_618_NL_The_table_of_Eleven.pdf+ The+\%E2\%80\%98Table+of+Eleven $\%$ E2\%80\%99\&hl=nl\&gl=nl\&pid=bl\& srcid=ADGEESii3iRDI3MyUHEJG4YoPbaGgBUTYoqEWFvFMAoI7sEoee8C7rjBqY4XJw1zG1Qqsq9BDmPojqSCDjquHRe2xvcHQjFbtrrYnv1qqbLmJS Ktn2H4QgaoKi576rC_TW1jI8Fl2v\&sig=AHIEtbSssJkidJkE59FcEPhZbH7bs154g 